This item was submitted to Loughborough's Research Repository by the author.

Items in Figshare are protected by copyright, with all rights reserved, unless otherwise indicated.

\title{
Effect of inspiratory muscle training on exercise tolerance in asthmatic individuals
}

PLEASE CITE THE PUBLISHED VERSION

http://dx.doi.org/10.1249/MSS.0b013e31821f4090

PUBLISHER

Lippincott, Williams \& Wilkins (? The American College of Sports Medicine

VERSION

AM (Accepted Manuscript)

LICENCE

CC BY-NC-ND 4.0

\section{REPOSITORY RECORD}

Turner, Louise A., Timothy D. Mickleborough, Alison K. McConnell, Joel M. Stager, Sandra Tecklenburg-Lund, and Martin R. Lindley. 2019. "Effect of Inspiratory Muscle Training on Exercise Tolerance in Asthmatic Individuals". figshare. https://hdl.handle.net/2134/11342. 
This item was submitted to Loughborough's Institutional Repository (https://dspace.lboro.ac.uk/) by the author and is made available under the following Creative Commons Licence conditions.

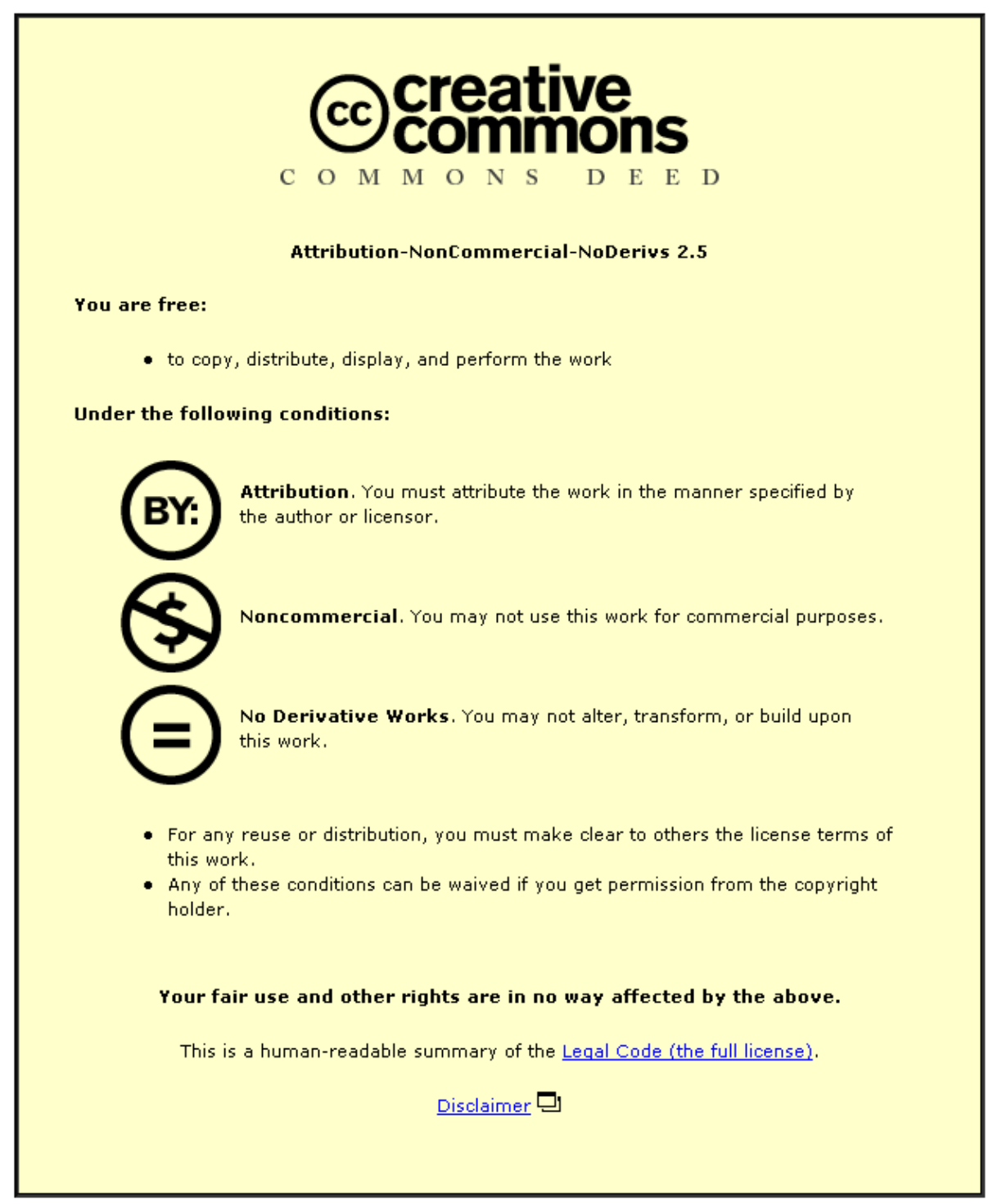

For the full text of this licence, please go to: http://creativecommons.org/licenses/by-nc-nd/2.5/ 


\section{Effect of Inspiratory Muscle Training on Exercise Tolerance in}

\section{Asthmatic Individuals}

Louise A. Turner ${ }^{1,2}$, Timothy D. Mickleborough ${ }^{1}$, Alison K. McConnell ${ }^{3}$, Joel M. Stager ${ }^{1}$,

Sandra Tecklenburg-Lund ${ }^{4}$, and Martin R Lindley ${ }^{5}$.

${ }^{1}$ Department of Kinesiology, Indiana University, Bloomington, IN, USA.

${ }^{2}$ Department of Sport and Exercise Science, Northumbria University, Newcastle upon Tyne, UK

${ }^{3}$ Centre for Sport Medicine and Human Performance, Brunel University, Uxbridge, Middlesex, UK

${ }^{4}$ Health and Human Performance, Nebraska Wesleyan University, Lincoln, NE, USA

${ }^{5}$ School of Sport, Exercise and Health Sciences, Loughborough University, Loughborough, Leicestershire, UK

Running Title: Inspiratory Muscle Training and Asthma

Funding Disclosures: None

\section{Address for Correspondence:}

Timothy D. Mickleborough, Ph.D., FACSM

Human Performance Laboratory

Department of Kinesiology

Indiana University

1025. E. $7^{\text {th }}$ Street, HPER 112

Bloomington, IN 47401

Phone: 812-855-0753

Fax: 812-855-3193

Email: tmickleb@indiana.edu 


\begin{abstract}
Purpose: The aim of this study was to determine the effects of inspiratory muscle training (IMT) on exercise tolerance, inspiratory muscle fatigue and the perception of dyspnea in asthmatic individuals. Methods: Using a matched, double-blind, placebo-controlled design, 15 clinicallydiagnosed asthmatics underwent either 6 wks of inspiratory muscle training (IMT, n=7) consisting of 30 breaths twice-daily at $50 \%$ maximum inspiratory pressure $\left(\mathrm{PI}_{\max }\right)$, or sham-IMT (PLA, $\mathrm{n}=8$ ) consisting of 60 breaths daily at $15 \% \mathrm{PI}_{\max }$. Time to the limit of exercise tolerance (Tlim) was assessed using constant power-output (70\% peak power) cycle ergometery. Inspiratory muscle fatigue was determined by comparing the pre- to post-exercise reduction in $\mathrm{PI}_{\max }$. Dyspnea during the Tlim test was evaluated at 2-min intervals using the Borg CR-10 scale. Results: There were no significant changes ( $p>0.05)$ in Tlim, inspiratory muscle fatigue, or perception of dyspnea in the PLA group following the intervention. In contrast, in the IMT group, $\mathrm{PI}_{\max }$ increased by $28 \%$, and Tlim by $16 \%(\mathrm{P}<0.05)$. Dyspnea during exercise was also reduced significantly by $16 \%(\mathrm{P}<0.05)$. The exercise induced fall in $\mathrm{PI}_{\max }$ was reduced from $10 \%$ pre-IMT, to $6 \%$, post-IMT $(\mathrm{P}<0.05)$, despite the longer Tlim. Pulmonary function remained unchanged in both the IMT and PLA groups. Conclusion: These data suggest that IMT attenuates inspiratory muscle fatigue, reduces the perception of dyspnea, and increases exercise tolerance. These findings suggest that IMT may be a helpful adjunct to asthma management that has the potential to improve participation and adherence to exercise training in this group. However, the perception of breathlessness is also an important signal of bronchoconstriction, and thus caution should be exercised if this symptom is abnormally low.
\end{abstract}

Key Words: respiratory muscle, dyspnea, asthma, exercise 


\section{INTRODUCTION}

Paragraph Number 1 Asthma is a disease associated with intermittent narrowing of the airways in which an individual experiences symptoms such as wheezing, chest tightness, coughing, and dyspnea (34). A characteristic of chronic asthma is that airway narrowing can alter airway function during exercise, and reduce the maximal-expiratory flow volume curve (15), which can result in airflow limitation and reduced exercise capacity (18).

Paragraph Number 2 Airway obstruction during exercise in asthmatic individuals is associated with increased inspiratory muscle work as a consequence of resistance to airflow and dynamic hyperinflation of the lung (increased end-expiratory lung volume, [EELV]) (15). The elevated work of breathing due to dynamic hyperinflation has been shown to be an important predictor of dyspnea in individuals with asthma (19), which is intensified by impairment in the contractile properties of the respiratory muscles (22). Increased work of breathing may also contribute to an increased risk of inspiratory muscle fatigue (39), which may exacerbate dyspnea and reduce exercise tolerance (24). Accordingly, it is reasonable to suggest that increasing the strength of the inspiratory muscles in people with asthma who experience increased inspiratory muscle work, may reduce the intensity of dyspnea, and improve exercise tolerance.

Paragraph Number 3 Inspiratory muscle training (IMT) has been shown to improve inspiratory muscle strength, exertional dyspnea and exercise tolerance in both healthy people and patients with COPD $(10,21)$. A limited number of studies have evaluated the effect of IMT in people with asthma, and have all demonstrated improved inspiratory muscle strength, and reduced asthma symptoms, as well as reductions in hospitalizations, absence from school or work, medication usage, dyspnea during loaded breathing, and improved pulmonary function 
(35-38). However, the influence of IMT upon exercise tolerance and exertional dyspnea in people with asthma currently remains unknown.

Paragraph Number 4 Therefore, the main aim of the present study was to investigate the effect of 6 wks of IMT on exercise tolerance and exertional dyspnea in asthmatic individuals. We hypothesized that IMT would: (1) increase inspiratory muscle strength and attenuate respiratory muscle fatigue, (2) reduce the perception of dyspnea, and (3) increase exercise tolerance.

\section{METHODS}

\section{Subjects}

Paragraph Number 5 Fifteen subjects ( 7 male, 8 female; mean \pm SEM age $24 \pm 1$ yr, stature $1.74 \pm 0.02 \mathrm{~m}$, body mass $76 \pm 4 \mathrm{~kg}$ ) with physician-diagnosed asthma were recruited to the study. All had mild to moderate persistent asthma, with a resting forced expiratory volume in 1-sec $\left(\mathrm{FEV}_{1}\right)$ of $>70 \%$ predicted and were taking physician prescribed maintenance medications. All subjects continued with their daily maintenance medications (stable dose) throughout the duration of the study (i.e. leukotriene receptor antagonists [LTRAs; $\mathrm{N}=5$ montelukast (Singulair $\left.\left.{ }^{\circledR}\right)\right]$; long-acting $ß_{2}$-agonists $[\mathrm{N}=4$,fluticasone propionate (Flovent $®$ ) and salmeterol (Advair $\left.{ }^{\circledR}\right)$ ]; long-acting $\beta_{2}$-agonists and LTRAs $[\mathrm{N}=5$ salmeterol (Advair $®$ ) and montelukast (Singulair $\left(\right.$ )], while short-acting $\beta_{2}$-agonists were discontinued $12 \mathrm{hr}$ prior to exercise testing; all medication use throughout the course of the study was recorded. Subjects were asked to refrain from exercising $24 \mathrm{hr}$ prior to testing, and to avoid caffeine and alcohol intake during this time period. Subjects were asked to maintain a normal diet throughout the duration of the study, and to avoid consuming food $2 \mathrm{hr}$ prior to exercise. Prior to testing each subject completed a health 
screening questionnaire, and provided written informed consent. All testing procedures and informed consent were approved by the Indiana University Human Subjects Review Board.

\section{Study Design}

Paragraph Number 6 Subjects reported to the laboratory on 4 separate occasions. During session 1 they performed a maximal incremental cycling test to determine peak power output (PPO). Sessions 2 and 3 were conducted pre-intervention, and consisted of a constant-power cycle ergometer test to the limit of tolerance (Tlim) at $\sim 70 \%$ PPO (session 2 was for familiarization purposes). Session 4 was a repeat of sessions 2 and 3, and was conducted after the 6-wk intervention period. All tests were separated by at least $48 \mathrm{hr}$ and were conducted at a similar time of day and under similar environmental conditions.

Paragraph Number 7 Following baseline measurements, subjects were assigned in a double-blind manner to either an inspiratory muscle training group (IMT; $n=7$ ) or placebo group (PLA; $\mathrm{n}=8$ ), and were matched across groups according each subjects' maximal inspiratory mouth pressure $\left(\mathrm{PI}_{\max }\right)$.

\section{Pulmonary function and maximal inspiratory pressure measurements}

Paragraph Number 8 Pulmonary function was assessed using a calibrated computerized pneumotachograph spirometer (Vmax 22, SensorMedics, Yorba Linda, CA) according to American Thoracic Society (ATS) recommendations (1), which require each subject to perform 3 acceptable spirograms, of which $\mathrm{FVC}, \mathrm{FEV}_{1}$ and $\mathrm{FEF}_{25-75 \%}$ value may not vary by more than $10 \%$. The largest value is reported.

Paragraph Number 9 Maximal inspiratory pressure $\left(\mathrm{PI}_{\max }\right)$ was measured using a portable hand-held mouth pressure meter (Micro Medical Ltd, Kent, UK) and used as an index of inspiratory muscle strength. All maneuvers were initiated from residual lung volume (RV) and 
were conducted in an upright-seated position. A minimum of 5 maneuvers at 30 -sec intervals were conducted, with the variability between the best three measurements less than $5 \%$ or within $5 \mathrm{~cm} \mathrm{H}_{2} \mathrm{O}$ (40). Measurements of pre- and post-exercise $\mathrm{PI}_{\max }$ were conducted prior to and following the intervention.

\section{Exercise Testing}

Paragraph Number 10 Peak power output was determined using a continuous maximal incremental ramp test (6Watt / 15-sec) on an electromagnetically braked cycle ergometer (Lode Excalibur, Netherlands). The test was terminated when the subject reached the limit of tolerance, or failed to maintain a pedaling cadence above $50 \mathrm{rpm}$. The power at which the subjects terminated exercise was defined as the peak power output (PPO).

Paragraph Number 11 Metabolic and ventilatory data were measured continuously using breath-by-breath indirect calorimetry (Vmax 22, SensorMedics, Yorba Linda, CA). Heart rate was monitored using a F1 Polar Heart Rate Monitor (Polar, Helsinki, Finland). Arterial oxygen saturation $\left(\mathrm{SaO}_{2}\right)$ was estimated using ear oximetry (model 47201A, Hewlett Packard). The oximeter was calibrated using an internal protocol prior to each test, according to the manufacturer's instructions.

Paragraph Number 12 The data generated from the maximal incremental ramp test (PPO) was used to determine the power output for the Tlim. The Tlim test was performed at a workload of $\sim 70 \%$ PPO until volitional fatigue. During the last 30 -sec of each minute, two maximum inspiratory capacity (IC) maneuvers (inspiration to maximal lung capacity) were performed. End-expiratory lung volume (EELV) was calculated by subtracting the maximum inspiratory capacity from the resting force vital capacity (FVC), with values expressed as a percentage of FVC. EILV was determined as the sum of EELV and $\mathrm{V}_{\mathrm{T}}$ (average of 10-20 
breaths). Dyspnea was assessed using the Borg scale (CR-10 scale) at 2-min intervals during the Tlim test.

\section{Training Intervention}

Paragraph Number 13 Inspiratory muscle training was completed using a pressurethreshold training device (POWERbreathe®, HaB International Ltd., UK). The IMT group performed 30 dynamic inspiratory efforts twice daily at a pressure-threshold load of $50 \%$ of $\mathrm{PI}_{\max }$ for 6 weeks. This specific protocol has been shown to elicit a number of changes in inspiratory muscle function, including strength, power and endurance $(3,27-29)$. The PLA group performed the training intervention once daily for 6 weeks at a pressure-threshold load equivalent to $15 \%$ of $\mathrm{PI}_{\max }$; this protocol has been shown to exhibit no changes in inspiratory muscle function $(3,28)$. Each breath was initiated from RV, with breathing frequency decreased to minimize hyperventilation-induced hypocapnia.

Paragraph Number 14 Compliance to training was monitored using a pressure sensor suspended within the main body of the inspiratory muscle trainer (28). The generation of a negative pressure exceeding the set point on the pressure switch caused a count to be registered. The cumulative number of pressure threshold changes were recorded and computed into total number of breaths. Physical activity diaries were used throughout the duration of the study to monitor training volume and intensity.

\section{Data Analysis}

Paragraph Number 15 Data were analyzed using SPSS version 17.0 statistical software. The data were assessed for normality using the Kolmogorov-Smirnov test and Levene's test was used to test for homogeneity of variance between tests. A one-way repeated measures ANOVA was used to analyze within group changes over time during the Tlim test. A Mauchly's test was 
conducted to determine if sphericity was violated. In cases where sphericity was violated, a Gieser-Greenhouse correction was applied. Within and between group interactions were analyzed using a two-way ANOVA with repeated measures. A Tukey post hoc analysis was performed to determine significant differences. Statistical significance was set at $\mathrm{p}<0.05$. Values are reported as mean $\pm \mathrm{SEM}$.

\section{RESULTS}

Paragraph Number 16 Baseline measurements of pulmonary function (Table 1) were within predicted normal limits and were not significantly different $(p>0.05)$ between the IMT and PLA groups. All parameters remained unchanged in both groups following the intervention. Peak power output achieved during the maximal incremental cycle test was not significantly different $(\mathrm{p}>0.05)$ between the IMT $(250 \pm 21 \mathrm{~W})$ and PLA $(255 \pm 24 \mathrm{~W})$ groups. In addition, peak aerobic capacity was not significantly different $(\mathrm{p}>0.05)$ between the IMT and PLA groups ( $\dot{\mathrm{V}} \mathrm{O}_{\text {2peak }}, 42.6 \pm 2.9 \mathrm{~mL} \cdot \mathrm{kg}^{-1} \cdot \mathrm{min}^{-1}$ and $40.2 \pm 2.2 \mathrm{~mL} \cdot \mathrm{kg}^{-1} \cdot \mathrm{min}^{-1}$, respectively). Subjects adhered well to the training intervention with a compliance of $94 \%$ and $92 \%$ in the IMT and PLA groups, respectively. Daily physical activity remained unchanged throughout the intervention period as reported by their physical activity logs.

Maximal Inspiratory Pressure (PI $\left.I_{\max }\right)$

Paragraph Number 17 Table 1 shows the mean pre- and post-exercise values for $\mathrm{PI}_{\max }$, before and after the training intervention. Baseline values for $\mathrm{PI}_{\max }$ were not significantly different $(\mathrm{p}>0.05)$ between the IMT and PLA group. Following 6 weeks of training, the IMT group demonstrated a significant increase $(\mathrm{p}<0.05)$ of $27.7 \pm 3.2 \%$ in $\mathrm{PI}_{\max }$, whilst no change ( $\mathrm{p}>0.05)$ in $\mathrm{PI}_{\max }$ occurred in the PLA group. 
Paragraph Number 18 Prior to the intervention, $\mathrm{PI}_{\max }$ decreased significantly $(\mathrm{p}<0.05)$ by $9.6 \pm 3.9 \%$ and $10.6 \pm 3.5 \%$ from pre- to post- exercise (index of inspiratory muscle fatigue) in both the IMT and PLA groups, respectively. Following IMT, the post-exercise decrease in $\mathrm{PI}_{\max }$ was significantly reduced $(\mathrm{p}<0.05)$ to $6.2 \pm 4.2 \%$ in the IMT group. There was no significant change ( $p>0.05)$ in inspiratory muscle fatigue in the PLA group following the intervention.

\section{Exercise Tolerance}

Paragraph Number 19 Prior to the training intervention there was no signficiant difference ( $p>0.05$ ) between groups in the time to the limit of exercise tolerance (Tlim) $[8.5 \pm$ 0.9 min for the IMT group and $9.1 \pm 0.9$ min for the PLA group]. Following IMT, exercise Tlim increased significantly $(\mathrm{p}<0.05)$ by $22 \%$, to $10.6 \pm 1.5 \mathrm{~min}$ in the IMT group. No significant change ( $p>0.05$ ) in the exercise Tlim was observed in the PLA group (Post-PLA, $8.5 \pm 1.3 \mathrm{~min}$ ).

\section{Metabolic and Ventilatory Responses during exercise}

Paragraph Number 20 The metabolic and ventilatory data from the constant-power Tlim test are shown in Table 2. All data are reported in the range of 0-5 min as all subjects sustained exercise for a minimum of $5 \mathrm{~min}$ both pre- and post- training intervention. In addition, comparisons were made at an end exercise point (isoend), and at a time point during the posttraining Tlim test that corresponded to the pre-training end point $\left(\mathrm{T}_{\text {base }}\right)$. Prior to training, there were no significant differences ( $p>0.05$ ) between the IMT and PLA group for any of the measured metabolic and ventilatory variables during exercise.

Paragraph Number 21 Following the training intervention, the PLA group exhibited no significant change ( $p>0.05)$ in any of the measured metabolic and ventilatory variables.

However, significant changes $(\mathrm{p}<0.05)$ in $\dot{\mathrm{V}} \mathrm{O}_{2}, \dot{\mathrm{V}}_{\mathrm{CO}_{2}}$, and $\dot{\mathrm{V}} \mathrm{E}^{/} \dot{\mathrm{V}} \mathrm{O}_{2}(\mathrm{P}<0.05)$ were observed following the training intervention in the IMT group (Table 2). $\dot{\mathrm{V}} \mathrm{O}_{2}$ decreased significantly by 
$6 \%$ at $\min 4$ and by $12 \%$ at the end point of exercise (Fig. 1). Similar changes were also noted for $\dot{\mathrm{V}} \mathrm{CO}_{2}$, which was significantly lower $(\mathrm{p}<0.05)$ at $\min 4(9 \%)$ and at the end of exercise $(11 \%)$ in the IMT group following the training intervention. All other metabolic and ventilatory variables remained unchanged $(\mathrm{p}>0.05)$ following training in the IMT group.

Paragraph Number 22 Figure 2 shows the end-inspiratory lung volume (EILV) and endexpiratory lung volume (EELV) responses to exercise, pre- and post- intervention for both the IMT (Fig 2a) and PLA (Fig 2b) groups. There was no significant change ( $p>0.05$ ) in EILV, from pre- to post- intervention, in either group at any time point during exercise. However, there was a significant decrease $(\mathrm{p}<0.05)$ in EELV at minute 5 of exercise in the IMT group following the intervention. EELV remained unchanged in the PLA group. The exercising expiratory flow rates of both groups are shown in Figure 3. Peak expiratory flow rate (PEFR) and mid-expiratory flow rate (MEFR) remained unchanged ( $p>0.05)$ in both the IMT and PLA groups following intervention.

\section{Dyspnea}

Paragraph Number 23 The perception of dypnea during exercise in the IMT and PLA group prior to the training intervention was not significantly different ( $p>0.05$ ) (Fig. 4). Pre- to post- IMT, dyspnea was significantly reduced at minute 4 (from $3.7 \pm 0.7$ to $3.0 \pm 0.5$ ) and at the end of exercise (from $5.9 \pm 0.8$ to $5.1 \pm 0.9$ ). No significant differences $(\mathrm{p}<0.05)$ in dyspnea ratings were observed in the PLA group from pre- to post- intervention at any time point during exercise.

\section{DISCUSSION}

Paragraph Number 24. The main findings of the present study are that asthmatic individuals performing $6 \mathrm{wks}$ of IMT: 1) increased inspiratory muscle strength and showed 
attenuation of exercise-induced inspiratory muscle fatigue and 2) reduced oxygen consumption and perception of dyspnea during exercise, and 3) increased Tlim during constant power exercise.

Paragraph Number 25 Inspiratory muscle strength increased by 27\% in the present study, which is similar in magnitude to that reported previously using pressure-threshold IMT in patients with asthma $(35,36)$. An increase in inspiratory muscle strength following IMT has been shown to be associated with an increase in diaphragm thickness $(6,8)$, and hypertrophy of type I and type II muscle fibers of the external intercostals muscles (25). Thus, changes in strength reflect structural remodeling within the inspiratory musculature.

Paragraph Number 26 Impaired inspiratory muscle strength prior to exercise has been shown to intensify exertional dyspnea in individuals with asthma (17), and may reduce exercise tolerance in these individuals. (24). Consistent with the results of this study, IMT has previously been shown to reduce the perception of dyspnea during exercise in healthy individuals $(28,29$, 32) and during pressure threshold inspiratory loading in asthmatic individuals (36). The increased inspiratory muscle work associated with increased airway resistance and dynamic hyperinflation is an important predictor of dyspnea during bronchoconstriction (19), and may be related to a number of factors such as reduced strength of the inspiratory muscles due to their shortened operating length (16), recruitment of additional accessory respiratory muscles (33), and increased inspiratory activity during expiration (20). Furthermore, the intensity of dyspnea during exercise in asthmatics is associated $(\mathrm{r}=0.72)$ with the degree of bronchoconstriction, diffusing capacity of the lung, and inspiratory muscle strength at rest (17).

Paragraph Number 27 Pulmonary function $\left(\mathrm{FEV}_{1}\right.$ and $\left.\mathrm{FVC}\right)$ at rest has previously been shown to increase by $\sim 12 \%$ following 3-6 months of IMT in moderate- to severe- asthmatics (35, 
36). In contrast, neither $\mathrm{FEV}_{1}$ nor FVC changed following 6 weeks of IMT in the present study, which may be due to the duration of the training intervention being insufficient, and/or the use of individuals with mild asthma, since previous studies have used subjects with moderate- to severe- asthma $(35,36)$. Therefore, our data suggest that the reduction in the perception of dyspnea that we observed was most likely due to the increase in inspiratory muscle strength following IMT, and not due to changes in lung function. Further, this study supports the presence of a negative correlation between change in inspiratory muscle strength and the intensity of dyspnea during an inspiratory loading task following IMT (36). Specifically, increasing inspiratory muscle strength following IMT would require a smaller percentage of maximal force generating capacity to produce the required pressure for a given change in volume, decreasing the central motor command and thus reducing the perception of effort (7).

Paragraph Number 28 Exertional dyspnea, which is one of the symptoms of asthma that is associated with impaired exercise tolerance (24), has been shown to be reduced by aerobic training $(13,26)$ and following bronchodilator administration (18). The novel finding of this study is that IMT can improve exercise tolerance and reduce the perception of dyspnea in recreationally active asthmatic individuals with mild asthma, suggesting a potential role for IMT as a complementary intervention in this population. However, it should also be noted that a reduction in the perception of dyspnea may be potentially dangerous in the small population of asthmatics who have a low perception of dyspnea, and may cause them to underestimate the severity of asthmatic exacerbations.

Paragraph Number 29 Exercise tolerance may be reduced in asthmatics in association with expiratory flow limitation and dynamic hyperinflation (increased EELV) during exercise (18). Participants in the present study demonstrated a progressive increase in EELV with 
increasing exercise duration; however, participants in the IMT group showed a tendency towards a reduction in the degree of hyperinflation during the first 5 minutes of exercise following IMT, and a significant attenuation at 5 minutes. There was a similar tendency for EILV to be reduced, and for $\mathrm{V}_{\mathrm{T}}$ to remain unchanged in the IMT group, post-intervention. Previous research has shown that an increase in EELV during voluntary hyperpnea increased the elastic work of breathing and elevated the oxygen cost of ventilation (5). Thus, the reduction in the extent of hyperinflation demonstrated in the present study may be associated with a lower level of inspiratory muscle work, and is consistent with the reduction in the oxygen consumption during exercise that was observed in the IMT group post-intervention.

Paragraph Number 30 Exercise in individuals with chronic asthma can induce airway narrowing that can modify airway function during exercise, thereby reducing the maximal-flow volume loop, and consequently the ventilatory capacity and ventilatory reserve (15). Emerging evidence suggests that the paradoxical bronchoconstriction occurring in airways of people with asthma after deep inhalation (DI) is normalized when the DI occurs against a pressure threshold load (14). The modification of airway caliber following DI may be explained by the slow rate cross bridge cycling in airway smooth muscle, termed the 'latched state', which results in increased smooth muscle stiffness $(9,12)$. It has been suggested that the chronic application of pressure-threshold loading may exert a beneficial influence upon airway smooth muscle by releasing it from its 'latched state' (14). Thus, it is possible that IMT may elicit subtle improvements in airway diameter and airflow limitation during exercise, thereby reducing dynamic hyperinflation and increasing exercise capacity. The fact that peak and mean inspiratory flow rates were unchanged post-IMT (Figure 3), yet EELV was slightly reduced (Figure 2), supports this notion, but further investigation is necessary to confirm this hypothesis. 
Paragraph Number 31 The finding that the oxygen cost of constant-power submaximal cycling exercise at $\sim 70 \% \dot{\mathrm{V}}_{2 \max }$ was reduced following IMT is consistent with previous studies that have also shown a reduction in $\dot{\mathrm{V}}_{2}$ during running (23), cycling (2), and in hypoxia (6) after IMT in healthy individuals. A reduced $\mathrm{V}_{2}$ may relate in part to improvements in respiratory muscle efficiency, which can be quantified as the additional oxygen consumption required for a given increase in ventilatory work (4). During incremental inspiratory loading, respiratory muscle efficiency has been shown to be lower in asthmatics compared to healthy individuals, and improved following the administration of a bronchodilator, which resulted in a reduction in hyperinflation and a corresponding increase of inspiratory muscle strength. Specifically, an increase in inspiratory muscle strength following IMT may decrease the relative intensity for a given amount of work, resulting in recruitment of fewer muscle fibers or delaying the recruitment of accessory respiratory muscles, thereby lowering the $\mathrm{O}_{2}$ requirement of the respiratory musculature. Thus, the reduced whole-body $\dot{\mathrm{VO}}_{2}$ following IMT in the present study may relate to changes in inspiratory muscle strength and/or changes in flow resistive work due to altered operating lung volumes during exercise.

Paragraph Number 32 Consistent with previous studies of IMT in healthy people, we observed an attenuation of exercise-induced inspiratory muscle fatigue, despite an increase in the time to the limit of tolerance $(11,30,32)$. There are two possible explanations for this, 1) stronger inspiratory muscles operate at a lower relative intensity post-exercise, which improves their fatigue resistance; 2) IMT attenuates the functional weakening of the inspiratory muscles that arises due to dynamic hyperinflation, which would otherwise lead to the recruitment of highforce generating, highly fatigable accessory muscle fibers, which exacerbate the development of respiratory muscle fatigue (33). The attenuation of inspiratory muscle fatigue may also have 
contributed to the improvement in exercise Tlim by delaying the onset of the inspiratory muscle metaboreflex (31).

\section{Conclusion}

Paragraph Number 33 This study has shown that 6 weeks of IMT in individuals with mild to moderate asthma, significantly increased inspiratory muscle strength, reduced inspiratory muscle fatigue, improved exercise tolerance, and reduced the perception of dyspnea during

cycling exercise at $\sim 70 \% \dot{\mathrm{VO}}_{2 \max }$ to the limit of tolerance. These data suggest that IMT may be a helpful adjunct to asthma management and has the potential to improve participation and adherence to exercise training in this group. However, it should also be noted that the perception of breathlessness is also an important signal of bronchoconstriction, and thus caution should be exercised if this symptom is abnormally low.

\section{Acknowledgements}

The inspiratory muscle trainers were provided by POWERbreathe ${ }^{\circledR}, \mathrm{HaB}$ International Ltd., UK.

Conflict of Interest statement: AKM acknowledges a beneficial interest in the POWERbreathe® inspiratory muscle trainer in the form of a royalty share on license income to the University of Birmingham. AKM provides consultancy services to HaB International Ltd.

The results of the present study do not constitute endorsement by ACSM. 


\section{REFERENCES}

1. American Thoracic Society. Standardization of Spirometry, 1994 Update . Am J Respir Crit Care Med. 1995;152(3):1107-1136.

2. Bailey SJ, Romer LM, Kelly J, Wilkerson DP, Dimenna FJ, Jones AM. Inspiratory muscle training enhances pulmonary $\mathrm{O} 2$ uptake kinetics and high-intensity exercise tolerance in humans. J Appl Physiol. 2010;109(2):457-468.

3. Caine M, McConnell, AK. Development and evaluation of a pressure threshold inspiratory muscle trainer for use in the context of sports performance. Sports Engineering. 2000;3(3):149-159.

4. Cherniack RM. The oxygen consumption and efficiency of the respiratory muscles in health and emphysema. J Clin Invest. 1959;38(3):494-499.

5. Collett PW, Perry C, Engel LA. Pressure-time product, flow, and oxygen cost of resistive breathing in humans. J Appl Physiol. 1985;58(4):1263-1272.

6. Downey AE, Chenoweth LM, Townsend DK, Ranum JD, Ferguson CS, Harms CA. Effects of inspiratory muscle training on exercise responses in normoxia and hypoxia. Respir Physiol Neurobiol. 2007;156(2):137-146.

7. el-Manshawi A, Killian KJ, Summers E, Jones NL. Breathlessness during exercise with and without resistive loading. J Appl Physiol. 1986;61(3):896-905.

8. Enright SJ, Unnithan VB, Heward C, Withnall L, Davies DH. Effect of high-intensity inspiratory muscle training on lung volumes, diaphragm thickness, and exercise capacity in subjects who are healthy. Phys Ther. 2006;86(3):345-354. 
9. Fredberg JJ, Inouye D, Miller B, et al. Airway smooth muscle, tidal stretches, and dynamically determined contractile states. Am J Respir Crit Care Med. 1997;156(6):1752-1759.

10. Geddes EL, O'Brien K, Reid WD, Brooks D, Crowe J. Inspiratory muscle training in adults with chronic obstructive pulmonary disease: an update of a systematic review. Respir Med. 2008;102(12):1715-1729.

11. Griffiths LA, McConnell AK. The influence of inspiratory and expiratory muscle training upon rowing performance. Eur J Appl Physiol. 2007;99(5):457-466.

12. Hai CM, Murphy RA. Cross-bridge phosphorylation and regulation of latch state in smooth muscle. Am J Physiol. 1988;254(1 Pt 1):C99-106.

13. Hallstrand TS, Bates PW, Schoene RB. Aerobic conditioning in mild asthma decreases the hyperpnea of exercise and improves exercise and ventilatory capacity. Chest. 2000;118(5):1460-1469.

14. How SC, Romer LM, McConnell AK. Acute effects of inspiratory pressure threshold loading upon airway resistance in people with asthma. Respir Physiol Neurobiol. 2009;166(3):159-163.

15. Johnson BD, Scanlon PD, Beck KC. Regulation of ventilatory capacity during exercise in asthmatics. J Appl Physiol. 1995;79(3):892-901.

16. Killian KJ, Gandevia SC, Summers E, Campbell EJ. Effect of increased lung volume on perception of breathlessness, effort, and tension. J Appl Physiol. 1984;57(3):686-691.

17. Killian KJ, Summers E, Watson RM, O'Byrne PM, Jones NL, Campbell EJ. Factors contributing to dyspnoea during bronchoconstriction and exercise in asthmatic subjects. Eur Respir J. 1993;6(7):1004-1010. 
18. Kosmas EN, Milic-Emili J, Polychronaki A, et al. Exercise-induced flow limitation, dynamic hyperinflation and exercise capacity in patients with bronchial asthma. Eur Respir J. 2004;24(3):378-384.

19. Lougheed MD, Fisher T, O'Donnell DE. Dynamic hyperinflation during bronchoconstriction in asthma: implications for symptom perception. Chest. 2006;130(4):1072-1081.

20. Martin J, Powell E, Shore S, Emrich J, Engel LA. The role of respiratory muscles in the hyperinflation of bronchial asthma. Am Rev Respir Dis. 1980;121(3):441-447.

21. McConnell AK. Respiratory muscle training as an ergogenic aid. J Exerc Sci Fit. 2009;7(2):S18-S27.

22. McConnell AK, Romer LM. Dyspnoea in health and obstructive pulmonary disease : the role of respiratory muscle function and training. Sports Med. 2004;34(2):117-132.

23. Mickleborough TD, Nichols T, Lindley MR, Chatham K, Ionescu AA. Inspiratory flow resistive loading improves respiratory muscle function and endurance capacity in recreational runners. Scand J Med Sci Sports. 2010;20(3):458-468.

24. O'Donnell DE, Revill SM, Webb KA. Dynamic hyperinflation and exercise intolerance in chronic obstructive pulmonary disease. Am J Respir Crit Care Med. 2001;164(5):770777.

25. Ramirez-Sarmiento A, Orozco-Levi M, Guell R, et al. Inspiratory muscle training in patients with chronic obstructive pulmonary disease: structural adaptation and physiologic outcomes. Am J Respir Crit Care Med. 2002;166(11):1491-1497. 
26. Robinson DM, Egglestone DM, Hill PM, Rea HH, Richards GN, Robinson SM. Effects of a physical conditioning programme on asthmatic patients. $N Z \mathrm{Med} J$. $1992 ; 105(937): 253-256$.

27. Romer LM, McConnell AK. Specificity and reversibility of inspiratory muscle training. Med Sci Sports Exerc. 2003;35(2):237-244.

28. Romer LM, McConnell AK, Jones DA. Effects of inspiratory muscle training on timetrial performance in trained cyclists. J Sports Sci. 2002;20(7):547-562.

29. Romer LM, McConnell AK, Jones DA. Effects of inspiratory muscle training upon recovery time during high intensity, repetitive sprint activity. Int J Sports Med. $2002 ; 23(5): 353-360$.

30. Romer LM, McConnell AK, Jones DA. Inspiratory muscle fatigue in trained cyclists: effects of inspiratory muscle training. Med Sci Sports Exerc. 2002;34(5):785-792.

31. Romer LM, Polkey MI. Exercise-induced respiratory muscle fatigue: implications for performance. J Appl Physiol. 2008;104(3):879-888.

32. Volianitis S, McConnell AK, Koutedakis Y, McNaughton L, Backx K, Jones DA. Inspiratory muscle training improves rowing performance. Med Sci Sports Exerc. 2001;33(5):803-809.

33. Ward ME, Eidelman D, Stubbing DG, Bellemare F, Macklem PT. Respiratory sensation and pattern of respiratory muscle activation during diaphragm fatigue. J Appl Physiol. $1988 ; 65(5): 2181-2189$.

34. Weiler JM. Exercise-induced asthma: a practical guide to definitions, diagnosis, prevalence, and treatment. Allergy Asthma Proc. 1996;17(6):315-325. 
35. Weiner P, Azgad Y, Ganam R, Weiner M. Inspiratory muscle training in patients with bronchial asthma. Chest. 1992;102(5):1357-1361.

36. Weiner P, Berar-Yanay N, Davidovich A, Magadle R, Weiner M. Specific inspiratory muscle training in patients with mild asthma with high consumption of inhaled beta(2)agonists. Chest. 2000;117(3):722-727.

37. Weiner P, Magadle R, Beckerman M, Berar-Yanay N. The relationship among inspiratory muscle strength, the perception of dyspnea and inhaled beta2-agonist use in patients with asthma. Can Respir J. 2002;9(5):307-312.

38. Weiner P, Magadle R, Massarwa F, Beckerman M, Berar-Yanay N. Influence of gender and inspiratory muscle training on the perception of dyspnea in patients with asthma. Chest. 2002;122(1):197-201.

39. Weiner P, Suo J, Fernandez E, Cherniack RM. The effect of hyperinflation on respiratory muscle strength and efficiency in healthy subjects and patients with asthma. Am Rev Respir Dis. 1990;141(6):1501-1505.

40. Wen AS, Woo MS, Keens TG. How many maneuvers are required to measure maximal inspiratory pressure accurately. Chest. 1997;111(3):802-807. 


\section{FIGURE LEGENDS}

Figure 1: $\mathrm{VO}_{2}$ response to constant power cycle ergometry to the limit of tolerance for both inspiratory muscle training (IMT, Fig. 1a) and placebo groups (PLA, Fig 1b) pre- and postintervention (mean \pm SEM). $\bullet$, pre-IMT; O, post-IMT; $\mathbf{\Delta}$, pre-PLA; $\Delta$, post-PLA. *denotes significant difference from pre-intervention $(\mathrm{p}<0.05),{ }^{\dagger}$ denotes significant difference from $\mathrm{T}_{\text {base }}$ $(\mathrm{p}<0.05)$.

Figure 2: End-inspiratory lung volume (EILV) and end-expiratory lung volume (EELV) responses to constant power cycle ergometry to the limit of tolerance for both inspiratory muscle training (IMT, Fig. 2a) and placebo groups (PLA, Fig. 2b) pre- and post-intervention (mean \pm SEM). •, pre-IMT; O, post-IMT; $\mathbf{\Delta}$, pre-PLA; $\Delta$, post-PLA. *denotes significant difference from pre-intervention $(\mathrm{p}<0.05)$.

Figure 3: Peak expiratory flow rate (PEFR, Fig. 3a \& 3b) and mid-expiratory flow rate (MEFR, Fig. 3c \& 3d) responses to constant power cycle ergometry to the limit of tolerance for both inspiratory muscle training (IMT) and placebo groups (PLA) pre- and post-intervention (mean \pm SEM). •, pre-IMT; O, post-IMT; $\mathbf{\Delta}$, pre-PLA; $\triangle$, post-PLA.

Figure 4: Dyspnea ratings during constant power cycle ergometry to the limit of tolerance for both inspiratory muscle training (IMT) and placebo groups (PLA) pre- and post-intervention (mean \pm SEM). •, pre-IMT; O, post-IMT; $\mathbf{\Delta}$, pre-PLA; $\Delta$, post-PLA. *denotes significant difference from pre-intervention $(\mathrm{p}<0.05)$. 


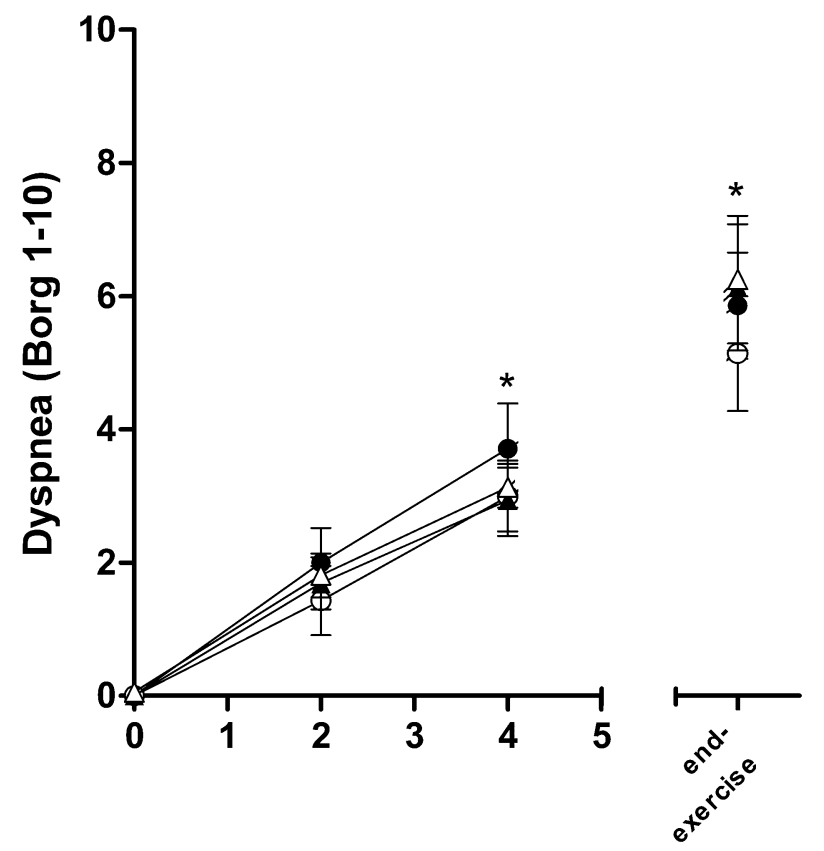

Time to the limit of tolerance (min)

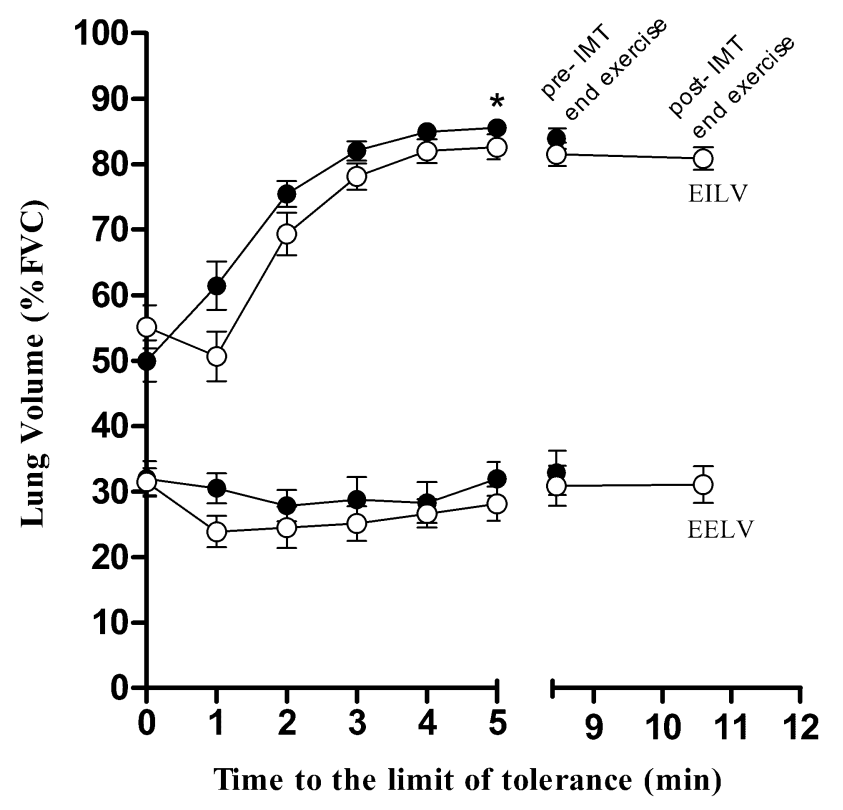

a

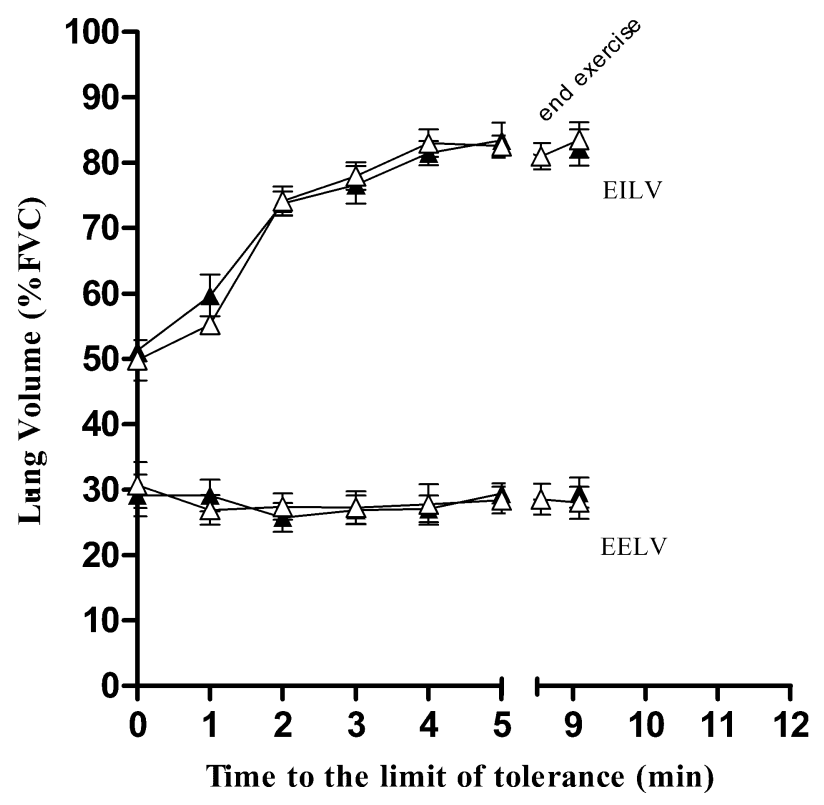

b 


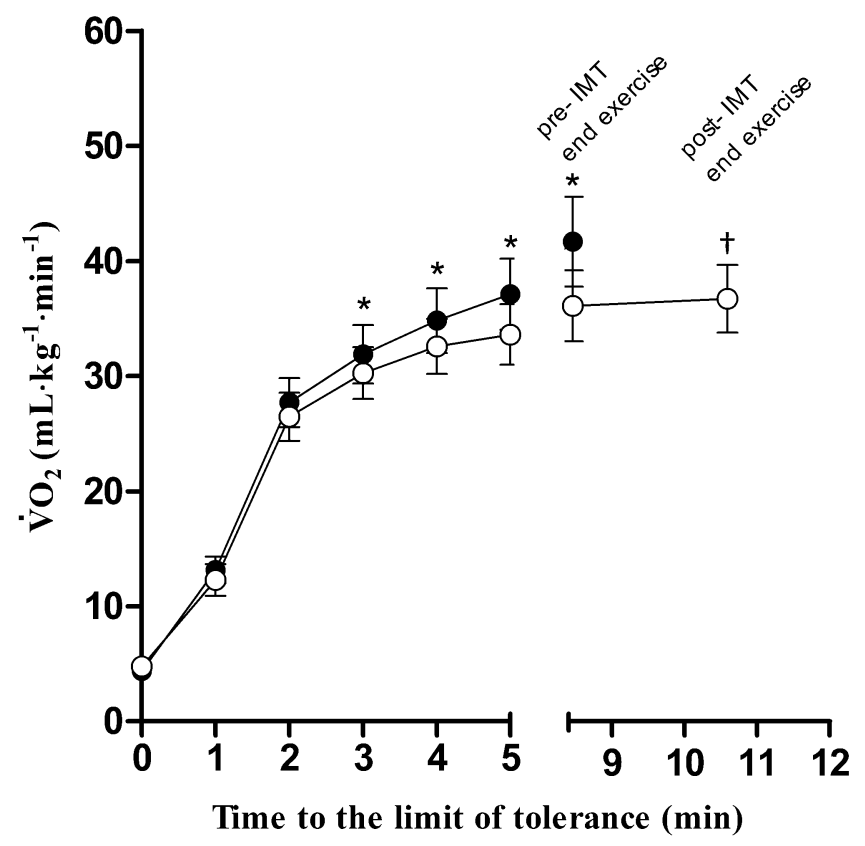

a

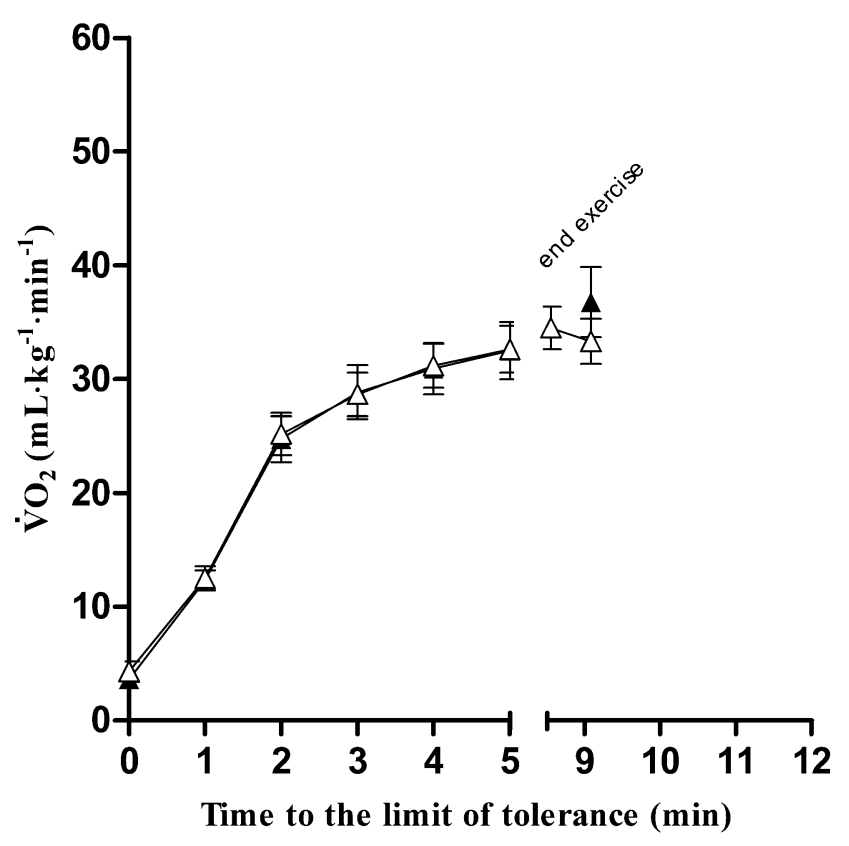

b

Table 1: Pulmonary function and inspiratory muscle strength

\begin{tabular}{|c|c|c|c|c|}
\hline & \multicolumn{2}{|c|}{ IMT } & \multicolumn{2}{|c|}{ PLA } \\
\hline & Pre & Post & Pre & Post \\
\hline \multicolumn{5}{|c|}{ Resting pulmonary function } \\
\hline FVC (L) & $4.33 \pm 0.26$ & $4.34 \pm 0.25$ & $4.58 \pm 0.36$ & $4.63 \pm 0.36$ \\
\hline$\%$ Predicted & $95 \pm 5$ & $95 \pm 5$ & $97 \pm 5$ & $98 \pm 5$ \\
\hline $\mathrm{FEV}_{1}(\mathrm{~L})$ & $3.61 \pm 0.22$ & $3.63 \pm 0.21$ & $3.71 \pm 0.26$ & $3.69 \pm 0.30$ \\
\hline$\%$ Predicted & $93 \pm 3$ & $93 \pm 3$ & $96 \pm 3$ & $95 \pm 4$ \\
\hline PEFR (L) & $7.19 \pm 0.50$ & $7.25 \pm 0.42$ & $7.40 \pm 0.30$ & $7.47 \pm 0.38$ \\
\hline$\%$ Predicted & $89 \pm 4$ & $90 \pm 4$ & $93 \pm 5$ & $92 \pm 3$ \\
\hline $\mathrm{FEF}_{25-75 \%}(\mathrm{~L})$ & $3.58 \pm 0.35$ & $3.74 \pm 0.39$ & $3.91 \pm 0.44$ & $3.94 \pm 0.53$ \\
\hline$\%$ Predicted & $87 \pm 9$ & $91 \pm 10$ & $93 \pm 9$ & $93 \pm 11$ \\
\hline
\end{tabular}




\section{Inspiratory muscle strength}

$\begin{array}{lrrrr}\text { Pre- exercise } \mathrm{PI}_{\max }\left(\mathrm{cmH}_{2} \mathrm{O}\right) & 114.6 \pm 10.1 & 145.4 \pm 11.7 * * & 114.3 \pm 10.3 & 120.6 \pm 9.2 \\ \text { Post- exercise } \mathrm{PI}_{\max }\left(\mathrm{cmH}_{2} 0\right) & 101.8 \pm 6.8^{*} & 134.1 \pm 8.0^{*} & 103.5 \pm 11.4^{*} & 109.0 \pm 8.6^{*}\end{array}$

Values are mean \pm SEM. FVC, forced vital capacity; $\mathrm{FEV}_{1}$, forced expiratory volume in 1 sec; PEFR, peak expiratory flow rate; FEF25-75\%, forced expiratory flow during $25-75 \%$ of vital capacity; $\mathrm{PI}_{\max }$, maximal inspiratory pressure. * denotes significant difference from pre- to post- exercise $(\mathrm{p}<0.05)$; $* *$ denotes significant difference from pre- to post- training $(\mathrm{p}<0.05)$. 
Table 2: Metabolic and ventilatory responses to constant-power cycling

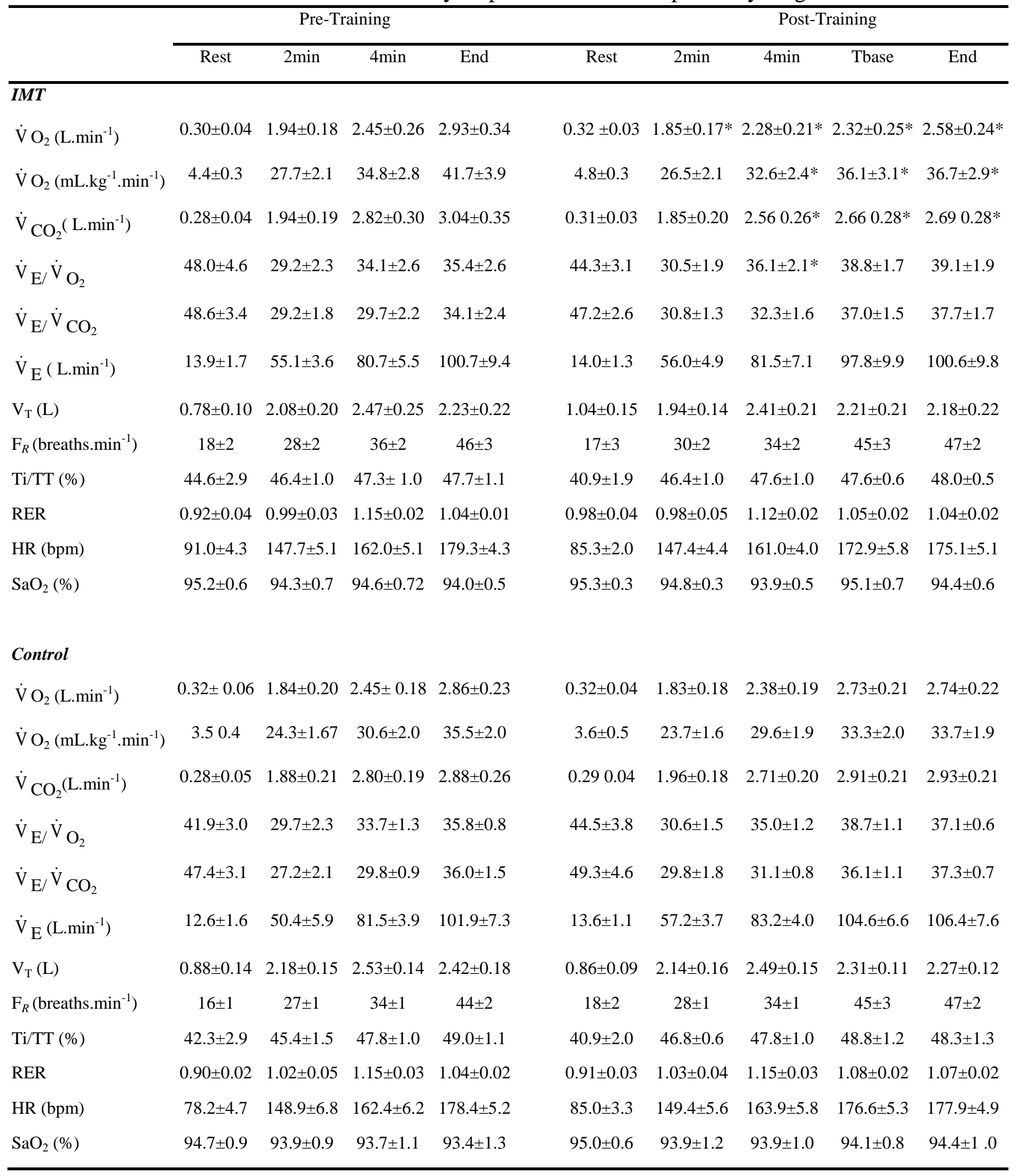


Values are mean \pm SEM. *denotes significantly different from pre-training $(\mathrm{p}<0.05) . \dot{\mathrm{V}} \mathrm{O}_{2}$, peak oxygen consumption; VE, minute ventilation; VT, tidal volume; FR, breathing frequency; Ti/TT, ratio of inspiratory time to total time; RER, respiratory exchange ratio; $\mathrm{SaO}_{2}$, arterial oxygen saturation; end, end exercise. 
